\title{
Nganjuk.Hitz: \\ Sistem Informasi Pariwisata Berbasis 360-degree Tourism Web Guna Mengembangkan Destinasi Wisata di Kabupaten Nganjuk
}

\author{
Nganjuk.Hitz: A Tourism Information System Based on a 360-degree Tourism Web \\ to Develop Tourism Destinations in Nganjuk Regency
}

\begin{tabular}{l|r}
\hline Dian Ahmad Sasmito & \\
Laililia Binti Mohamad Sofyan & \\
(1Fakultas Ilmu Sosial, Universitas Negeri Malang, Malang, Indonesia & Article history: \\
${ }^{2}$ Fakultas Ilmu Pendidikan, Universitas Negeri Malang, Malang, Indonesia & Submitted: 11 January 2021 \\
${ }^{3}$ Fakultas Ekonomi dan Bisnis, Universitas Airlangga, Surabaya, Indonesia & Accepted: 30 March 2021 \\
${ }^{\bowtie}$ dian.ahmad.170721@students.um.ac.id & Published: 3 April 2021 \\
\hline
\end{tabular}

Abstract: Sustainable development era has provided the government to increase foreign exchange earnings from non-oil and gas. Nganjuk Regency is one of the regions in East Java that has a number of tourism potential. However, lack of efforts from local governments and tourism managers in the delivery of tourist information, make tourists less aware of the beauty and uniqueness of tourism in Nganjuk Regency. Purpose of this study are designing Nganjuk.Hitz, a $360^{\circ}$ Tourism Web and Explain the results of its implementation. Employing Research and Development (R\&D) method that uses the ADDIE model, data collection uses observation, documentation, and questionnaires using purposive sampling method and uses descriptive data analysis. Results of the study, after testing through web browsers, the tourism information system based on Nganjuk.Hitz $360^{\circ}$ Tourism Web is successfully stated. Usability test results state that respondents feel this tourism information system is interesting, easy to understand, complying the needs, easy and convenient to use, and in turn, are interested to visit the tourism destination.

Keywords: $360^{\circ}$ Tourism Web; Nganjuk regency; Nganjuk.Hitz; tourism

Abstrak: Era pembangunan berkelanjutan telah memacu pemerintah untuk meningkatkan penerimaan devisa dari sektor nonmigas. Kabupaten Nganjuk merupakan salah satu daerah di Jawa Timur yang memiliki sejumlah potensi wisata. Namun kurangnya upaya dari pemerintah daerah dan pengelola pariwisata dalam penyampaian informasi wisata, membuat wisatawan kurang menyadari keindahan dan keunikan pariwisata yang ada. Tujuan dari penelitian ini adalah merancang Nganjuk.Hitz $360^{\circ}$ Tourism Web dan menjelaskan hasil pelaksanaannya. Menerapkan metode Research and Development (R\&D) yang menggunakan model ADDIE, pengumpulan datanya menggunakan observasi, dokumentasi, dan kuesioner menggunakan metode purposive sampling serta menggunakan analisis data deskriptif. Hasil penelitian, setelah dilakukan pengujian melalui web browser berhasil dinyatakan sistem informasi pariwisata berbasis Nganjuk.Hitz $360^{\circ}$ Tourism Web ini. Sedangkan hasil uji usability menyatakan bahwa responden merasa sistem informasi pariwisata ini menarik, mudah dipahami, memenuhi kebutuhan, mudah dan nyaman digunakan, dan pada akhirnya tertarik untuk mengunjungi destinasi wisata tersebut.

Kata kunci: $360^{\circ}$ Tourism Web; Kabupaten Nganjuk; Nganjuk.Hitz; pariwisata 
Nganjuk.Hitz: Sistem Informasi Pariwisata Berbasis 360-degree Tourism Web...

Dian Ahmad Sasmito, Wahyu Pratama Putra, \& Laililia Binti Mohamad Sofyan

\section{Pendahuluan}

Indonesia sebagai salah satu negara yang menyepakati untuk menerapakan tujuan pembangunan berkelanjutan (SDG's) dengan mengambil langkah strategis untuk menyukseskannya (Badan Pusat Statistik, 2016). Berlangsungnya era SDG's ini, pemerintah berusaha meningkatkan pemasukan devisa yang berasal dari sektor non migas. Salah satu sektor yang cukup potensial dijadikan andalan yaitu industri pariwisata. Pariwisata juga telah mengalami ekspansi dan diversifikasi berkelanjutan dan menjadi salah satu sektor ekonomi terbesar (Susana, Alvi, \& Persada, 2017). Hal tersebut didukung dengan kontribusi sektor pariwisata terhadap produk domestik bruto (PDB) pada tahun 2014 mencapai 9\% atau Rp.946,09 triliun (Lembaga Penyelidikan Ekonomi dan Masyarakat, 2016). Namun demikian, di antara 17 tujuan pembangunan berkelanjutan, masih terdapat masalah yang ada di Indonesia, terutama di sektor pariwisata, antara lain adalah strategi pemasaran pariwisata yang belum efektif (Pusat Kajian Anggaran Badan Keahlian DPR, 2016). Dalam kajian tersebut, ditemukan bahwa strategi pemasaran pariwisata di Indonesia masih kurang mengedapankan aspek teknologi dan branding destinasi wisata yang dipasarkan.

Di sisi lain, pada era sekarang tren teknologi informasi dan komunikasi berkembang sangat pesat. Jumlah pengguna internet dan sosial media skala nasional lebih dari 50\% dibandingkan populasi Indonesia (Gambar 1), maka berbagai informasi mengenai produk dan destinasi pariwisata dapat disampaikan pada calon wisatawan melalui media internet terutama platform media sosial (Kementerian Pariwisata, 2018). Dengan adanya peluang tersebut, internet dan social media menjadi media pemasaran pariwisata yang menjanjikan (Nurmi, 2017; Prasetya, 2018).

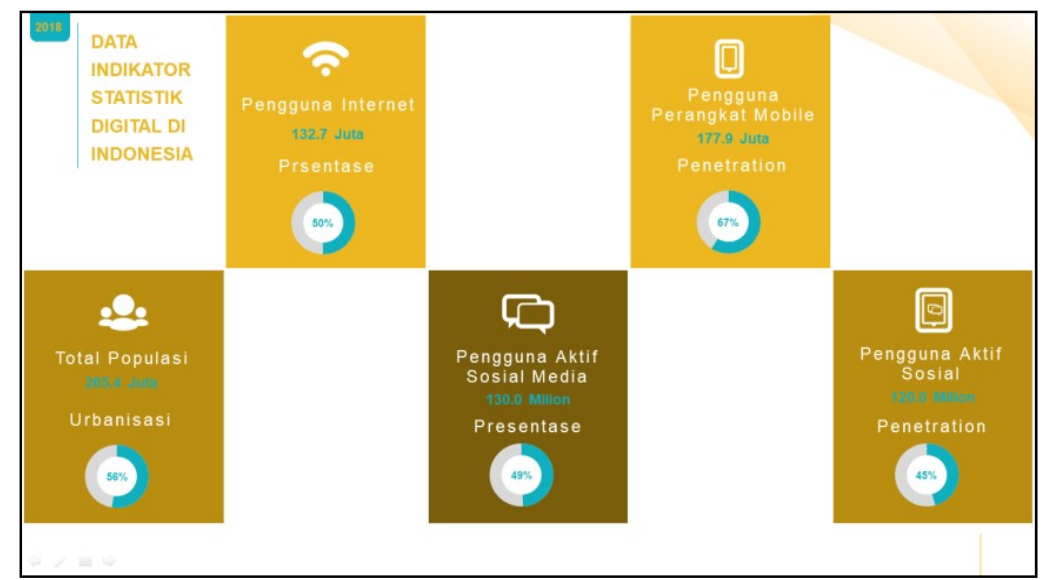

Gambar 1. Kondisi aktivitas pengguna media digital di Indonesia (Sumber: Kementerian Pariwisata, 2018)

Kabupaten Nganjuk sebagai salah satu daerah di Provinsi Jawa Timur, dengan potensi pariwisata yang menjanjikan mulai dari wisata alam, budaya, sejarah hingga kuliner, namun kunjungan dan perkembangan pariwisata di Kabupaten Nganjuk masih kalah bersaing dengan daerah lain (Badan Pusat Statistik, 2019). Hal seperti ini dimungkinkan terjadi karena para pemangkunya gagal dalam pengenalan pasar pariwisata, gagal dalam mengemas wisata, gagal menganalisis potensi wisata, dan gagal melakukan koordinasi antar-pihak ([Suhendroyono, 2013] dalam Hariyanto, 2015). Rendahnya promosi juga menjadi hal yang mendasar dalam perkembangan pariwisata di Kabupaten Nganjuk. Calon wisatawan merasa kesulitan dalam mencari informasi, lokasi, dan arah objek wisata serta mengetahui kondisi yang menampilkan 
keindahan destinasi wisata (secara visual), padahal setiap destinasi wisata yang ada di Kabupaten Nganjuk memiliki keindahan atau panorama yang sangat memukau.

Rendahnya promosi terhadap pariwisata di Kabupaten Nganjuk sangat mempengaruhi peningkatan kunjungan wisatawan. Terbukti pada tahun 2016 kunjungan wisatawa domestik dan mancanegara di Kabupaten Nganjuk sebesar 293.386 wisatawan, sedangkan di tahun 2017 mengalami penurunan dengan kunjungan 288.112 wisatawan, sementara di tahun 2018 mengalami penurunan lagi sebanyak 212.915 wisatawan (Badan Pusat Statistik, 2019). Data kunjungan jumlah wisatawan tersebut menunjukkan bahwa pariwisata di Kabupaten Nganjuk belum mampu menarik minat wisatawan. Jumlah wisatawan di Kabupaten Nganjuk masih rendah dibanding wilayah di sekitarnya yang mencapai 500.000 hingga jutaan orang per tahunnya. Di era digital saat ini, tentunya media promosi yang menarik dan platform yang memudahkan calon wisatawan sangat dibutuhkan untuk memperkenalkan destinasi wisata di Nganjuk.

Salah satu cara untuk mengatasi hal tersebut adalah dengan mengembangkan pengolahan data dan informasi pariwisata dalam bentuk sebuah sistem informasi menggunakan platform $360^{\circ}$ tourism web. Konsep kreatif dari web pariwisata tersebut dilengkapi fitur foto $360^{\circ}$ view dengan teknik borderless (tanpa batas) dan seamless (tidak terpotong), sehingga dapat melihat sekeliling destinasi wisata (Berger et al., 2014). Pengguna dapat melihat sekeliling secara $360^{\circ}$ dan merasakan pengalaman 'pernah berada' di destinasi wisata dan tertarik untuk berkunjung (Osman, Wahab, \& Ismail, 2009; Kelling, Väätäjä, \& Kauhanen, 2017).

\section{Metode Penelitian}

\section{Model}

Jenis penelitian ini merupakan Research and Development (R\&D), sebab dalam penelitian ini mengembangkan sebuah sistem, yaitu sistem informasi pariwisata. Jenis penelitian ini sangat tepat digunakan untuk mengembangkan sistem informasi pariwisata untuk sekarang dan masa mendatang. Model yang digunakan dalam pengembangan ialah model ADDIE (Assume, Design, Development, Implementation, Evaluation) dikarenakan lebih rasional dan memiliki langkahlangkah yang sistematis dalam pengembangan produk ini (Mulyatiningsih, 2011: 179). Tahapan atau langkah-langkah dalam penelitian dan pengembangan ini adalah sebagai berikut:

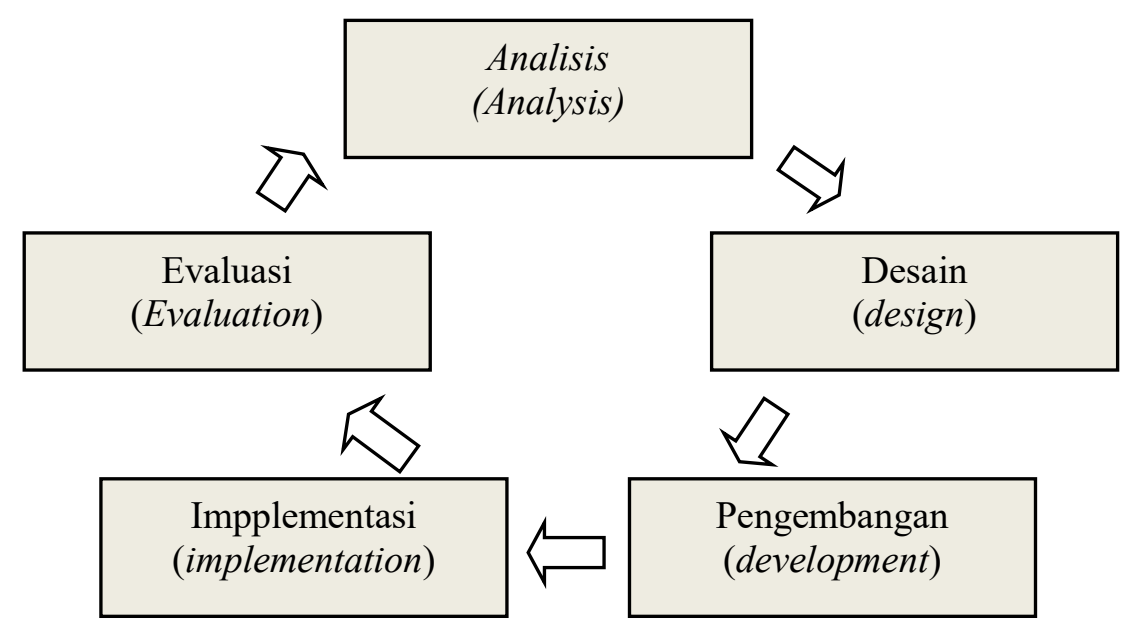

Gambar 2. Tahapan Pengembangan Nganjuk.Hitz 
1. Tahap Analisis

Tahap ini mengidentifikasi masalah potensi pariwisata di Kabupaten Nganjuk, mengindentifikasi inovasi atau solusi yang sesuai dengan permasalahan, dan pemikiran tentang inovasi yang akan dikembangkan yaitu $360^{\circ}$ Tourism Web.

2. Tahap Desain

Tahap ini merupakan tahap perancangan konsep sistem informasi pariwisata berbasis $360^{\circ}$ Tourism Web yang akan dikembangkan, meliputi penentuan bentuk, layanan, basis, dan beberapa unsur dari $360^{\circ}$ Tourism Web.

3. Tahap Pengembangan

Tahap pengembangan adalah proses mewujudkan desain yang telah dirancang menjadi kenyataan, meliputi 1) pengambilan foto dan video $360^{\circ}$, 2) mengunggah ke google stret view, dan 3) Mengembangkan website pariwisata di https://nganjukhitz.wixsite.com/tourism, serta tahapan 4) Pembelian hosting dan domain, dan 5) Launching setelah diketahui hasil evaluasi berjalan dengan baik.

4. Tahap Implementasi

Tahap ini adalah uji coba produk sebagai langkah nyata untuk menerapkan $360^{\circ}$ Tourism Web yang telah dikembangkan. Implementasi tersebut berupa pengujian akses melalui web browser dan implementasi ke calon wisatawan.

5. Tahap Evaluasi

Tahap ini merupakan proses untuk melihat apakah produk yang dibuat berhasil, sesuai dengan harapan awal atau tidak.

\section{Teknik Pengumpulan Data}

Teknik pengumpulan data yang digunakan oleh peneliti adalah:

a. Angket (Kuesioner): Kuesioner yang digunakan adalah kuesioner tertutup yakni sudah disediakan pilihan jawabannya (Sugiyono, 2008: 142). Angket tersebut digunakan untuk mengetahui tanggapan calon wisatawan terkait Nganjuk.Hitz yang diuji secara teknik random sampling. Pemilihan teknik sampel tersebut dikarenakan calon wisatwan terdiri dari berbagai kalangan tanpa ada kualifikasi tertentu, sehingga pemilihan secara acak dapat memudahkan peneliti.

b. Dokumentasi: Digunakan untuk mengambil foto dan video $360^{\circ}$ setiap sampel objek wisata.

c. Observasi: Digunakan untuk mengetahui kondisi objek pariwisata dan mendapatkan data lapangan mengenai pengelolaan pariwisata.

d. Studi literatur: Pengumpulan data ini didapat dari kepustakaan seperti buku, majalah, naskah, dan dokumen lainnya (Koentjaraningrat, 1983: 420). Dalam penelitian ini, studi kepustakaan yang digunakan berupa artikel jurnal dan buku sebagai landasan awal melakukan penelitian dan utamanya sebagai data pendukung hasil observasi di lapangan. 


\section{Analisis Data}

Teknik analisis data yang digunakan adalah statistik deskriptif yang bertujuan untuk memberikan deskripsi mengenai subjek penelitian. Deskripsi tersebut berdasarkan data yang diperoleh dan subjek yang diteliti (Azwar, 1998: 126). Analisis data tersebut dapat dilakukan dengan tahapan sebagai berikut:

1. Editing: pengecekan atau pengoreksian data primer dan sekunder tentang potensi destinasi wisata dan $360^{\circ}$ Tourism $\mathrm{Web}$ yang telah terkumpul, tujuannya untuk menghilangkan kesalahan-kesalahan yang terdapat pada pencatatan di lapangan dan bersifat koreksi.

2. Coding (Pengkodean): Langkah ini dilakukan dengan cara memasukkan kode ke setiap data yang memiliki kategori atau nilai yang sama. Hal tersebut ditujukan untuk mengubah menjadi data kuantitatif. Penggunaan kode yang dibuat berbentuk angka tersebut sebagai identitas untuk dianalisis. Hal ini tentunya untuk mempermudah dalam pemberian nilai nantinya.

3. Skor atau Nilai: Merupakan tahap dengan memberikan nilai, yang mulanya berupa pernyataan kualitatif menjadi data kuantitatif sesuai kriteria berikut (Hendryadi, 2017):

Tabel 1: Pedoman penilaian kuesioner

\begin{tabular}{cc}
\hline Data Kualitatif & Nilai (Data Kuantitaif) \\
\hline Sangat Setuju & 1 \\
Setuju & 2 \\
Cukup Setuju & 3 \\
Kurang Setuju & 4 \\
Sangat Kurang Setuju & 5 \\
\hline
\end{tabular}

Selanjutnya data tersebut dimasukkan rumus berikut untuk memperoleh rata-rata:

$$
\begin{array}{ll} 
& \\
\text { Keterangan: } \quad & \bar{X}=\frac{\sum X}{N} \\
\quad \sum_{N} X & =\text { skor rata-rata } \\
& =\text { jumlah skor } \\
& =\text { jumlah penilai }
\end{array}
$$

Setelah mendapatkan skor rata-rata, kemudian dicocokkan sesuai dengan kriteria yang berada pada tabel 2 . Kriteria tersebut didapatkan hasil dari jumlah indikator yang telah ditentukan kemudian dibuat skala likert dengan 5 opsi.

Tabel 2: Skala Likert penilaian kuesioner

\begin{tabular}{cc}
\hline Rerata Skor & Klasifikasi \\
\hline $5-4,2$ & Sangat Setuju \\
$3,4-4,2$ & Setuju \\
$2,6-3,4$ & Cukup Setuju \\
$1,8-2,6$ & Kurang Setuju \\
$<1,8$ & Sangat Kurang Setuju \\
\hline
\end{tabular}


4. Tabulasi: Langkah ini merupakan bagian tahap akhir dengan membuat tabel sesuai data yang diolah dengan rata-rata nilai yang diperoleh beserta kriterianya. Tabel tabulasi menunjukan data yang telah diolah dan nantinya dapat dianalisis.

\section{Rancangan Nganjuk.Hitz Berbasis $360^{\circ}$ Tourism Web}

Perancangan Nganjuk.Hitz diawali dengan mengelompokkan pariwisata di Kabupaten Nganjuk sebagai berikut:

a. Wisata Alam dan Budaya: Air Terjun Sedudo, Air Terjun Singokromo, Watu Lawang, Bukit Batu Songgong, Candi Ngetos, Air Terjun Roro Kuning, Pura Kerta Bhuwana, Goa Margo Tresno, dan Klenteng Hok Yoe Kiong.

b. Wisata Kota: Taman Rekreasi Anjuk Ladang, Taman Kota Pandan Wilis, Museum Anjuk Ladang, Alun-alun Nganjuk, dan The Legend Water Park.

c. Pagelaran: Siraman Air Terjun Sedudo, Pawai/Kirab Budaya, Pagelaran Wayang Kulit, dan Kebyar Tahun Baru.

Situs pariwisata Nganjuk.Hitz selain menyediakan informasi terkait destinasi wisata, tetapi juga menerima layanan pemesanan akomodasi seperti:

a. Paket wisata: paket tersebut di dalamnya menyediakan paket wisata untuk perorangan atau individu, paket keluarga, paket rombongan, dan paket pasangan atau couple.

b. Hotel dan restoran: Layanan ini menyajikan pemesanan hotel dan restoran.

c. Transportasi dan biro perjalanan: layanan ini menyajikan fasilitas transportasi untuk mengakses objek wisata yang dituju.

d. Toko souvenir: memberikan layanan terkait informasi lokasi pusat toko souvenir atau oleholeh dari objek wisata yang dituju.

Hal tersebut sebagai platform satu pintu dalam melayani kebutuhan pariwisata bagi wisatawan. Selain itu, untuk meningkatkan daya tarik wisatawan, Nganjuk.Hitz dirancang memiliki teknologi yang disebut $360^{\circ}$ Cinematic View. Teknologi ini mampu memvisualisasikan destinasi wisata secara $360^{\circ}$ dengan bantuan VR Glasses (kaca mata realitas virtual) sehingga wisatawan diberikan pandangan destinasi wisata seolah-olah berada di tempat tersebut.

Saran dalam penelitian ini adalah saat mengoperasikan mesin, pekerja dapat menggunakan sarung tangan agar adonan kue kembang waru tetap aman dari bakteri serta melakukan perawatan pada mesin secara rutin agar mesin selalu prima dan tidak menghambat produktivitas. Untuk penelitian selanjutnya, perancangan mesin dapat mempertimbangkan aspek-aspek lain selain dari ukuran tubuh manusia, seperti aspek konsumsi energi dan kondisi lingkungan kerja.

\section{Layanan Nganjuk.Hitz Berbasis $360^{\circ}$ Tourism Web}

\section{Layanan Informasi Pariwisata}

Layaknya sistem informasi pada umumnya, Nganjuk.Hitz menyediakan layanan informasi destinasi wisata yang terbagi menjadi 4 bagian yaitu informasi wisata alam, wisata kota, pagelaran seni dan budaya, serta sorotan utama (Gambar 3). 


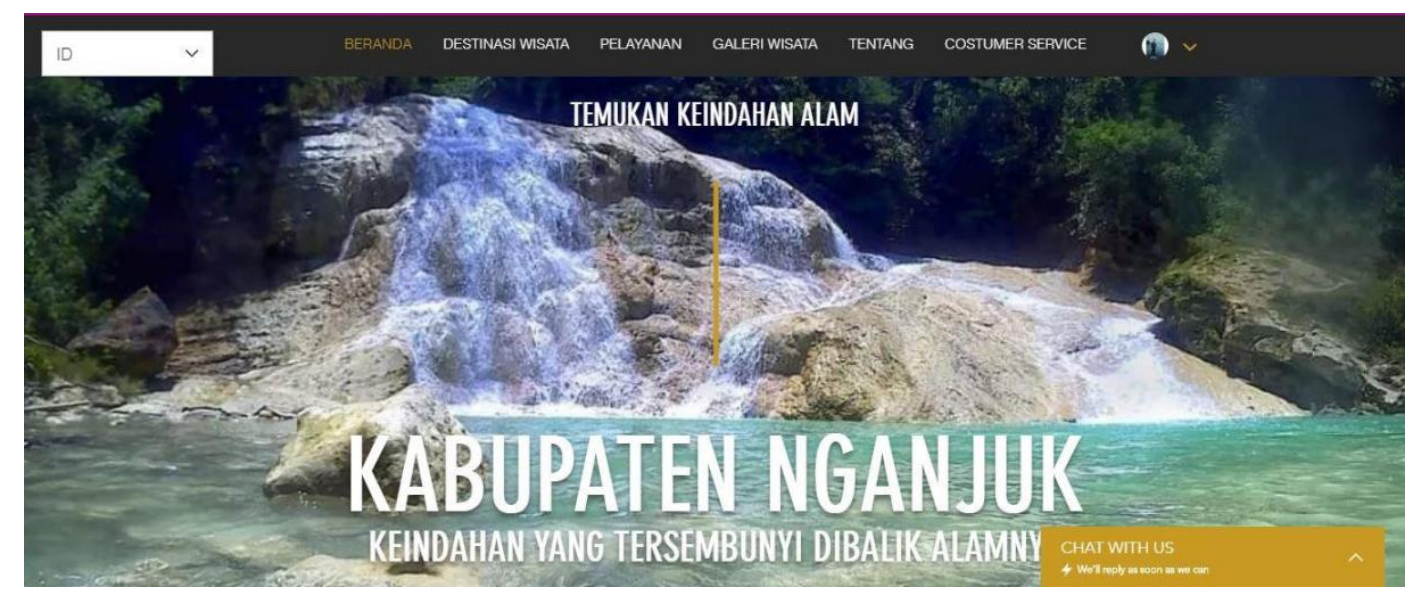

Gambar 3. Layanan Informasi Pariwisata

\section{Layanan Akomodasi}

Layanan akomodasi di website Nganjuk.Hitz terbagi menjadi: 1) Paket wisata, 2) Hotel dan restoran, 3) Transportasi dan Biro Perjalanan, dan 4) Toko dan Souvenir. Semua layanan ini dapat dilakukan dengan membuka informasi dan pemesanan melalui Nganjuk.Hitz. Layanan tersebut akan menjadi platform satu pintu yang memudahkan calon wisatawan dalam mengakses informasi dan layanan (Gambar 4).

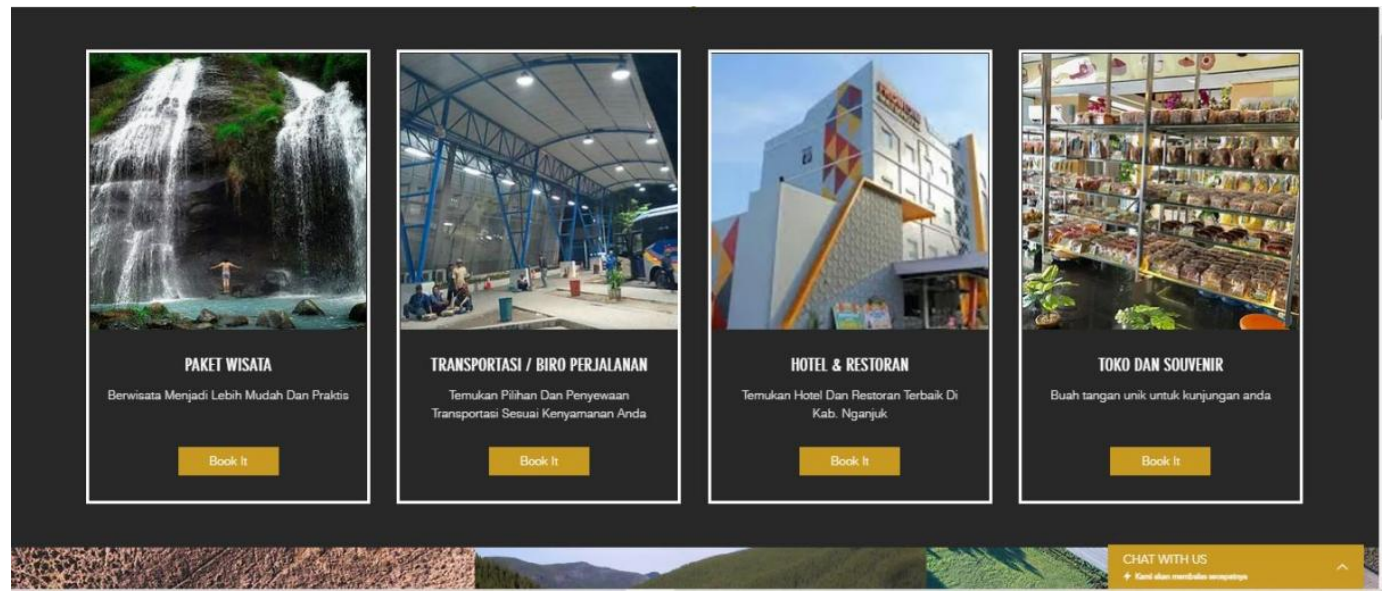

Gambar 4. Layanan Akomodasi

\section{Layanan Visualisasi $360^{\circ}$ Destinasi Wisata}

Hal unik yang menonjol dari website pariwisata Nganjuk.Hitz ialah terdapatnya fitur visualisasi $360^{\circ}$ dari destinasi wisata sehingga calon wisatawan dapat memperkirakan kejadian seolah-olah berada di lokasi wisata tersebut. Pengalaman virtual ini akan memberikan first impression yang memukau untuk calon wisatawan. Penggunaan VR Glasses akan memberikan pengalaman virtual yang lebih nyata dan dikombinasikan dengan website platform pariwisatanya (Gambar 5). 
Nganjuk.Hitz: Sistem Informasi Pariwisata Berbasis 360-degree Tourism Web...

Dian Ahmad Sasmito, Wahyu Pratama Putra, \& Laililia Binti Mohamad Sofyan

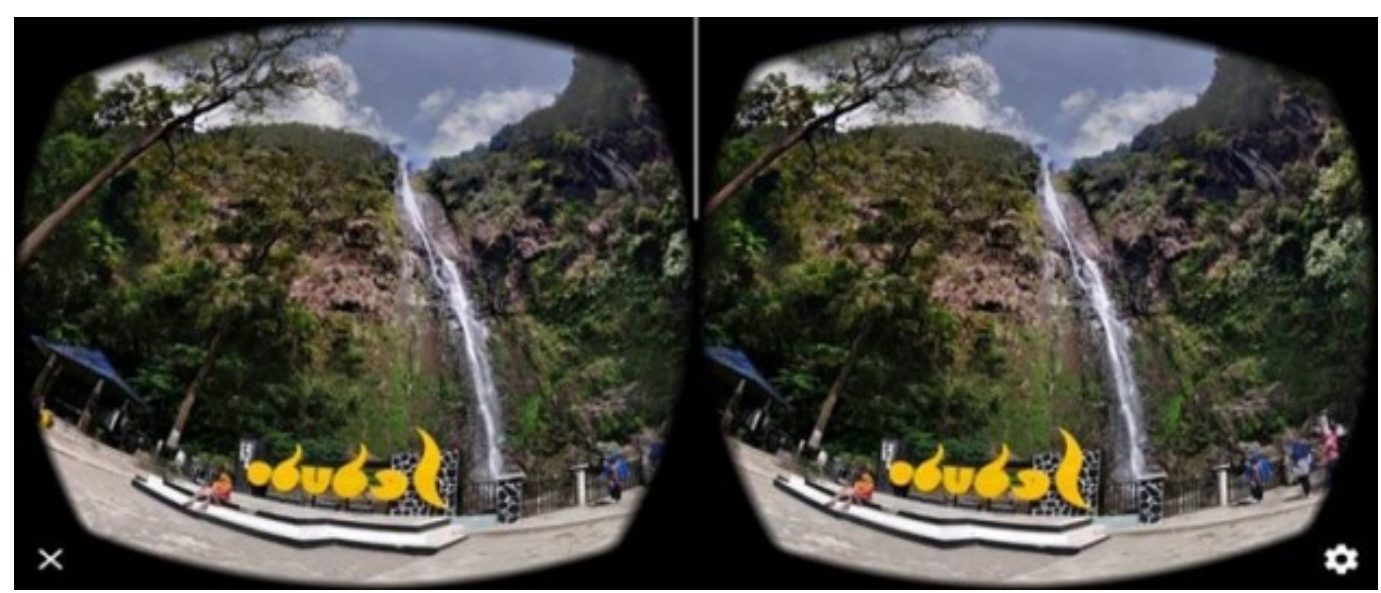

Gambar 5: Layanan Visualisasi $360^{\circ}$ Destinasi Wisata

\section{Implementasi Nganjuk.Hitz Berbasis $360^{\circ}$ Tourism Web}

\section{Hasil Pengujian Nganjuk.Hitz dengan Web Browser}

Pengujian sistem informasi pariwisata berbasis web browser dilakukan pada smartphone dengan jaringan akses internet pada tanggal 25 Maret 2021. Pengujian ini ditujukan apakah sistem informasi pariwisata berbasis $360^{\circ}$ Tourism Web mampu beroperasi dengan baik melalui media uji coba tersebut. Dari perangkat tersebut terdapat tiga web browser yang digunakan untuk mengakses. Berikut hasil pengujian di beberapa web browser.

Tabel 3. Hasil Uji Coba Browser

\begin{tabular}{clc}
\hline Media & Web Browser & Hasil \\
\hline \multirow{3}{*}{ Smartphone } & Mozilla Firefox & Berhasil (Gambar 6) \\
& Google Chrome & Berhasil (Gambar 7) \\
& Microsoft Edge & Berhasil (Gambar 8) \\
\hline
\end{tabular}

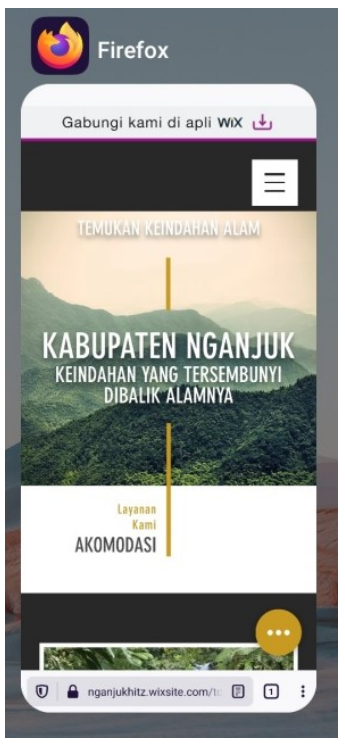

Gambar 6: Pengujian dengan Mozilla Firefox

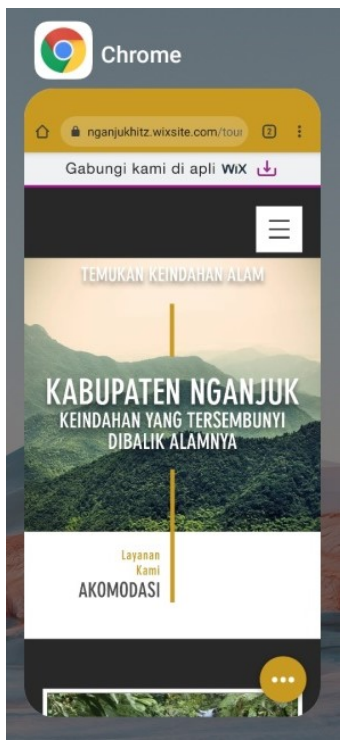

Gambar 7: Pengujian dengan Google Chrome

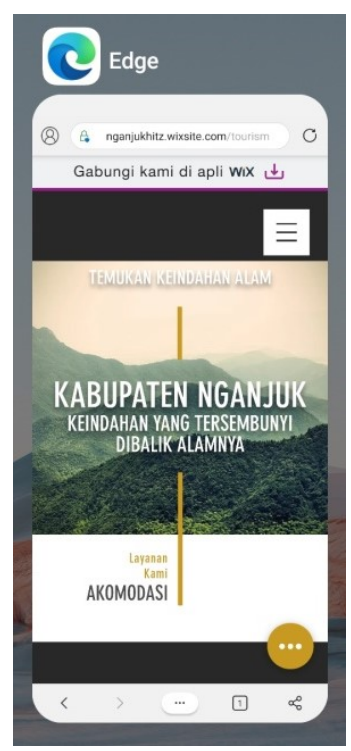

Gambar 8: Pengujian dengan Microsft Edge 
Berdasarkan pengujian menggunakan web browser didapatkan hasil jika dengan ketiga jenis web browser dinyatakan berhasil. Keberhasilan pengujian dapat diidentifikasi dengan dapat diaksesnya Nganjuk.Hitz di ketiga web browser. Terbukti saat pengujian menggunakan firefox, chrome, dan edge web pariwisata ini tidak terjadi bug atau kesalahan. Selain itu, dari ketiga web browser ini Nganjuk.Hitz dapat diakses dengan lancar, begitu pula saat membuka fitur $360^{\circ}$ virtual reality. Di samping itu kecepatan dalam membuka Nganjuk.Hitz dapat diuji coba menggunakan Google Speed Test, dengan kecepatan skor membuka yaitu 90 (gambar 9). Hasil pengujian tersebut menunjukkan bahwa Nganjuk.Hitz memiliki kecepatan akses yang baik dalam membuka situs, hal ini juga tergantung dengan kecepatan internet. Berdasarkan hal tersebut tidak terjadi kesalahan dalam perancangan sistem informasi pariwisata berbasis $360^{\circ}$ Tourism Web yang dapat digunakan sumber informasi wisatawan dengan mudah.

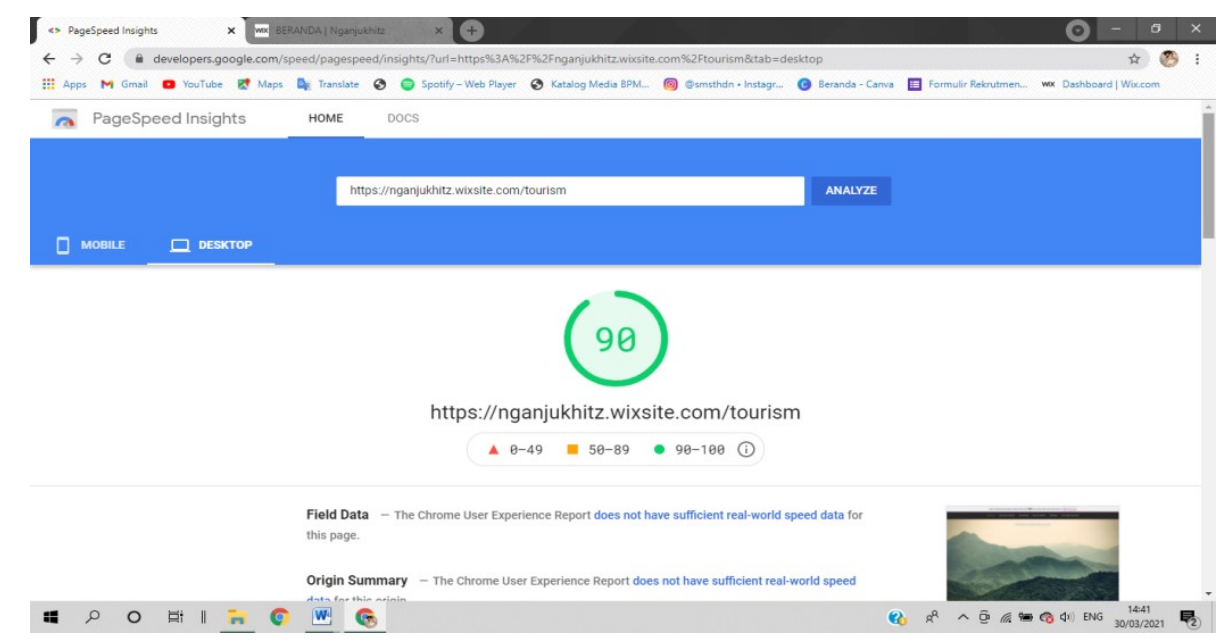

Gambar 9: Pengujian Kecepatan Akses Nganjuk.Hitz Dengan Google Speed Test

\section{Hasil Pengujian Nganjuk.Hitz secara Usability}

Pengujian ini dilakukan bersama masyarakat atau calon wisatawan dari berbagai kalangan pada bulan Januari 2021. Pengguna melakukan penilaian sistem informasi dengan menggunakan media kuesioner. Hasil kuesioner tersebut dapat ditarik kesimpulan apakah sistem informasi yang dibangun telah sesuai dengan tujuan atau tidak. Kuesioner tersebut diberikan pada 30 responden dan disebarkan menggunakan teknik sampling yaitu Simple Random Sampling yang disebarkan kepada beberapa pengguna dari kalangan masyarakat dan wisatawan. Berikut adalah pertanyaan dan hasil kuesioner yang telah dipresentasikan:

Tabel 4. Hasil Pengujian Responden

\begin{tabular}{|c|c|c|c|c|c|c|c|}
\hline \multirow{2}{*}{ Indikator Keyakinan } & \multicolumn{5}{|c|}{ Skor } & \multirow{2}{*}{ Rata } & \multirow{2}{*}{ Kriteria } \\
\hline & SS & $\mathbf{S}$ & CS & $\mathbf{T S}$ & STS & & \\
\hline \multirow{2}{*}{$\begin{array}{l}\text { Apakah tampilan dan fitur Nganjuk.Hitz } \\
\text { menarik? }\end{array}$} & 105 & 32 & 3 & - & - & \multirow{2}{*}{4,66} & \multirow{2}{*}{$\begin{array}{l}>4,2 \\
(\mathrm{SS})\end{array}$} \\
\hline & $(21 *)$ & $(8 *)$ & $\left(1^{*}\right)$ & - & - & & \\
\hline \multirow{2}{*}{$\begin{array}{l}\text { Apakah informasi yang dsediakan oleh } \\
\text { Nganjuk.Hitz mudah dimengerti? }\end{array}$} & 120 & 8 & 9 & 2 & - & \multirow{2}{*}{4,76} & \multirow{2}{*}{$\begin{array}{c}>4,2 \\
(\mathrm{SS})\end{array}$} \\
\hline & $\left(24^{*}\right)$ & $(2 *)$ & $\left(3^{*}\right)$ & $\left(1^{*}\right)$ & - & & \\
\hline
\end{tabular}


Nganjuk.Hitz: Sistem Informasi Pariwisata Berbasis 360-degree Tourism Web...

Dian Ahmad Sasmito, Wahyu Pratama Putra, \& Laililia Binti Mohamad Sofyan

\begin{tabular}{|c|c|c|c|c|c|c|c|}
\hline \multirow{2}{*}{$\begin{array}{l}\text { Apakah Nganjuk.Hitz sesuai dengan } \\
\text { kebutuhan? }\end{array}$} & 115 & 28 & - & - & - & \multirow{2}{*}{4,76} & \multirow{2}{*}{$\begin{array}{l}>4,2 \\
(\mathrm{SS})\end{array}$} \\
\hline & $(23 *)$ & $(7 *)$ & - & - & - & & \\
\hline \multirow{2}{*}{$\begin{array}{l}\text { Apakah Nganjuk.Hitz mudah dan nyaman } \\
\text { digunakan? }\end{array}$} & 100 & 32 & 6 & \multirow{2}{*}{-} & \multirow{2}{*}{-} & \multirow{2}{*}{4,6} & \multirow{2}{*}{$\begin{array}{l}>4,2 \\
(\mathrm{SS})\end{array}$} \\
\hline & $(20 *)$ & $(8 *)$ & $(2 *)$ & & & & \\
\hline \multirow{2}{*}{$\begin{array}{l}\text { Apakah setelah melihat Nganjuk.Hitz anda } \\
\text { tertarik untuk berkunjung? }\end{array}$} & 105 & 36 & \multirow{2}{*}{ - } & \multirow{2}{*}{-} & \multirow{2}{*}{ - } & \multirow{2}{*}{4,7} & \multirow{2}{*}{$\begin{array}{l}>4,2 \\
(\mathrm{SS})\end{array}$} \\
\hline & $(21 *)$ & $(9 *)$ & & & & & \\
\hline
\end{tabular}

Keterangan:

SS : Sangat Setuju

S : Setuju

CS : Cukup Setuju

TS : Tidak Setuju

STS : Sangat Tidak Setuju

Berdasarkan proses perhitungan skala jawaban dari responden disimpulkan sebagai berikut:

- 70\% (21) dari 30 responden menyatakan sangat setuju jika informasi di Nganjuk.Hitz ini menarik dengan rata-rata skor 4,66. Hasil ini menunjukkan jika mayoritas tertarik pada tampilan dan fitur yang diberikan;

- $80 \%$ (24) dari 30 responden menyatakan sangat setuju jika Nganjuk.Hitz mudah dimengerti. Dengan rata-rata skor 4,76 yang berarti sangat setuju dengan berbagai latar belakang masyarakat merasa mudah mengerti informasi yang tersedia. Terdapat 1 responden yang tidak setuju karena notabene berlatarbelakang sebagai seorang petani dengan penguasaan teknologi yang rendah;

- 77\% (23) dari 30 responden menyatakan sangat setuju jika Nganjuk.Hitz ini sesuai dengan kebutuhan dengan rata-rata skor 4,76. Hal ini menunjukkan bahwa keberadaan platform media promosi pariwisata seperti ini tepat dengan kebutuhan masa kini;

- 67\% (20) dari 30 responden dengan rata-rata skor 4,6 menyatakan sangat setuju jika Nganjuk.Hitz ini mudah dan nyaman dalam penggunaanya. Terutama pada fitur $360^{\circ}$, responden atau calon wisatawan tinggal mengarahkan smartphone-nya kearah yang diinginkan; dan

- $70 \%$ (21) dari 30 responden menyatakan ingin berkunjung ke destinasi wisata yang dilihat di Nganjuk.Hitz. Dengan rata-rata skor 4,7 menunjukan jika adanya inovasi sistem informasi pariwisata berbasis $360^{\circ}$ Tourism Web ini mampu menarik minat wisatawan untuk berkunjung ke destinasi wisata.

\section{Peran Nganjuk.Hitz terhadap Pengembangan Destinasi Wisata dan Manfaatnya untuk Masyarakat}

Melalui inovasi Nganjuk.Hitz, pariwisata di Kabupaten Nganjuk mampu memiliki nilai tambah sehingga dapat menarik minat wisatawan untuk berkunjung ke destinasi wisata. Nilai tambah yang dimaksudkan yaitu dikenalnya destinasi wisata oleh wisatawan dengan akses yang mudah. 
Dibuktikan dengan kelengkapan fitur aplikasi Nganjuk.Hitz yang mencakup berbagai aspek mulai dari detail destinasi wisata, akses transportasi, hotel dan restoran. Selain itu value added yang membedakan dengan destinasi wisata dari daerah lain dapat ditunjukkan melalui budaya, adat istiadat, dan kebiasaan masyarakat Kabupaten Nganjuk khususnya yang berdekatan dengan destinasi wisata. Di samping dua nilai tambah sebelumnya, berbagai menu kuliner unggulan juga dijadikan sebagai ciri khas Kabupaten Nganjuk yang ditawarkan pada menu restoran.

Masyarakat dapat dikatakan sejahtera jika sepenuhnya kebutuhan primernya seperti sandang, pangan, dan papan dapat dipenuhi. Dengan adanya income yang salah satunya dari pengelolaan wisata, kebutuhan primer tersebut dapat terpenuhi dengan baik (Istianah \& Nihayatuzzain, 2020). Sebagai inovasi sistem informasi pariwisata berbasis $360^{\circ}$ Tourism Web, Nganjuk.Hitz membantu memudahkan masyarakat untuk mendapatkan income melalui pengelolaan destinasi wisata di Kabupaten Nganjuk. Hal itu dibuktikan dengan keandalan Nganjuk.Hitz sebagai media promosi dan layanan wisata yang diproyeksikan akan mampu meningkatkan kunjungan wisatawan.

Pengenalan pariwisata secara digital akan membantu masyarakat dalam melakukan pengelolaan sumber daya alam yang berupa panorama pariwisata sebagai sumber penghasilan masyarakat. Wisatawan yang melakukan kunjungan destinasi wisata secara langsung akan membantu menstabilkan pendapatan masyarakat pelaku pariwisata. Hal ini nantinya dapat dibuktikan dengan naiknya permintaan atas jasa penginapan seperti hotel dan vila serta ragam kuliner yang termasuk variabel pendapatan masyarakat pelaku pariwisata (Desiati, 2013; Nurmayasari, 2017). Secara fungsional, berjalannya kedua basis program tersebut akan menjadikan pundi perekonomian masyarakat Kabupaten Nganjuk semakin stabil. Selain itu, aktivitas pengelolaan pariwisata juga mampu menumbuhkan sikap kewirausahaan (entrepreneurship) bagi masyarakat, sehingga dapat meningkatkan penghasilan dan menunjang kesejahteraan masyarakat Kabupaten Nganjuk.

\section{Kesimpulan}

Nganjuk.Hitz menjadi salah satu wadah untuk mempromosikan pariwisata Kabupaten Nganjuk secara digital dengan memanfaatkan $360^{\circ}$ Tourism Web. Sistem informasi pariwisata ini didesain sebagai platform satu pintu, yang memudahkan calon wisatawan dalam mengakses informasi. Proses pengembangan Nganjuk. Hitz mengombinasikan antara web by design dengan fitur $360^{\circ}$ view. Hasil implementasi Nganjuk.Hitz menyatakan dapat digunakan dari 3 jenis web browser (Chrome, Firefox, dan Edge) tanpa terjadi bug. Responden juga menyatakan merasa jika Nganjuk.Hitz menarik, mudah dimengerti, sesuai kebutuhan, mudah dan nyaman digunakan, serta merasa tertarik untuk mengunjungi destinasi wisata tersebut. Sistem informasi pariwisata ini disimpulkan dapat mempromosikan destinasi wisata dan mampu mempermudah calon wisatawan. Sebagai bagian dari penelitian R\&D, platform Nganjuk.Hitz akan dikembangkan lagi untuk dapat menambah kemanfaatannya untuk promosi wisata di Kabupaten Nganjuk. Dengan demikian, perekonomian dan kesejahteraan pelaku pariwisata dapat semakin baik dan terjamin. 
Nganjuk.Hitz: Sistem Informasi Pariwisata Berbasis 360-degree Tourism Web...

Dian Ahmad Sasmito, Wahyu Pratama Putra, \& Laililia Binti Mohamad Sofyan

\section{Referensi}

Azwar, S. (1998). Metode Penelitian. Yogyakarta: Pustaka Pelajar.

Badan Pusat Statistik (2016). Potret Awal Tujuan Pembangunan Berkelanjutan di Indonesia. Jakarta: BPS RI.

Badan Pusat Statistik (2019). Kabupaten Nganjuk Dalam Angka 2019. Nganjuk: BPS RI Kabupaten Nganjuk.

Berger, P. E., Matsuura, J. P., Barrios, A., Hopkins, P., Wagner, M. T., \& Weston, M. (2013). Analyzing the benefits of utilizing $360^{\circ}$ panoramic photo survey technology on a shell offshore platform. In SPE Middle East Intelligent Energy Conference and Exhibition. OnePetro. https://doi.org/10.2118/167382-MS

Desiati, R. (2013). Pemberdayaan masyarakat melalui pengelolaan program desa wisata. Diklus, 17(1). Retrieved from https://journal.uny.ac.id/index.php/diklus/article/view/2894

Hariyanto, A. (2015). Perancangan Sistem Informasi Pariwisata Indonesia Berbasis Web Services. In Seminar Nasional Informatika (SEMNASIF) (Vol. 1, No. 1). Retrieved from http://jurnal.upnyk.ac.id/index.php/semnasif/article/view/826

Hendryadi, H. (2017). Validitas isi: tahap awal pengembangan kuesioner. Jurnal Riset Manajemen Dan Bisnis (JRMB) Fakultas Ekonomi UNIAT, 2(2), 169-178. https://doi.org/10.36226/jrmb.v2i2.47

Istianah, D., \& Nihayatuzzain, N. (2020). Intervensi Komunitas Spedagi dalam Pemberdayaan Ekonomi Masyarakat Berbasis Potensi Lokal di Pasar Papringan Temanggung. Amalee: Indonesian Journal of Community Research and Engagement, 1(2), 159-171. https://doi.org/10.37680/amalee.v1i2.411

Kelling, C., Väätäjä, H., \& Kauhanen, O. (2017). Impact of device, context of use, and content on viewing experience of 360-degree tourism video. In Proceedings of the 16th International Conference on Mobile and Ubiquitous Multimedia (MUM '17). Association for Computing Machinery, New York, NY, USA, 211-222. DOI: https://doi.org/10.1145/3152832.3152872

Kementerian Pariwisata (2018). Rencana Strategis 2018-2019. Jakarta: Kementerian Pariwisata RI

Koentjaraningrat (1983). Metode-Metode Penelitian Masyarakat. Jakarta: Gramedia.

Lembaga Penyelidikan Ekonomi dan Masyarakat (2016). Laporan Akhir: Kajian Dampak Sektor Pariwisata Terhadap Perekonomian Indonesia. Jakarta: Universitas Indonesia.

Mulyatiningsih, E. (2011). Metode Penelitian Terapan Bidang Pendidikan. Bandung: Alfabeta.

Nurmayasari, D. (2017). Strategi Kelompok Sadar Wisata (Pokdarwis) Dalam Pengembangan Pariwisata Di Desa Canggu Kecamatan Badas Kabupaten Kediri. Publika, 5(1). Retrieved from https://jurnalmahasiswa.unesa.ac.id/index.php/publika/article/view/18711

Nurmi, N. (2017). Membangun Website Sistem Informasi Dinas Pariwisata. Edik Informatika, 1(2), 1-6. https://doi.org/10.22202/ei.2015.v1i2.1418

Osman, A., Wahab, N., \& Ismail, M. (2009). Development and Evaluation of an Interactive 360 Virtual Tour for Tourist Destinations. Journal of Information Technology Impact, 9 (3), 173-172.

Retrieved

from https://www.researchgate.net/publication/268730854 Development and Evaluation of an Interactive 360 Virtual Tour for Tourist Destinations 
Prasetya, A. B. (2018). Pengembangan Komunikasi Publik dan pariwisata berbasis internet pada website dinas pariwisata pemerintah kota malang. WACANA: Jurnal Ilmiah Ilmu Komunikasi, 17(2), 135-142. https://doi.org/10.32509/wacana.v17i2.645

Pusat Kajian Anggaran Badan Keahlian DPR (2016). Buletin APBN. Jakarta. DPR RI.

Sugiyono (2008). Metode Penelitian Kuantitatif Kualitatif dan R\&D. Bandung : Alfabeta

Susana, I., Alvi, N. N., \& Persada, C. (2017). Perwujudan Pariwisata Berkelanjutan melalui Pemberdayaan Masyarakat Lokal di Pulau Pahawang, Pesawaran, Provinsi Lampung. TATALOKA, 19(2), 117-128. https://doi.org/10.14710/tataloka.19.2.117-128 